\title{
Relationship between Cognitive Engagement and Academic Achievement among Kenyan Secondary School Students
}

Erick Wara

KISII-KENYA

\author{
Dr Peter JO Aloka
}

Department of Psychology \& Educational Foundations, Jaramogi Oginga Odinga University of science \& technology

\section{Dr Benson Charles Odongo}

Department of Early childhood Education Studies, Jaramogi Oginga Odinga University of science \& technology

Doi: $10.2478 / \mathrm{mjss}-2018-0026$

\begin{abstract}
The purpose of this study was to investigate the relationship between student cognitive engagement and academic achievement of secondary school students of Manga Sub County, Nyamira County, Kenya. The study was hinged on the Self Determination theoretical perspective. The mixed methods approach was employed, and within it, the concurrent triangulation design was adopted. From the target population of 1750 form four students, 35 Principals and 35 Guidance and Counselling teachers, 312 students (out of 316 expected), 11 Principals and 11 Guidance and counselling teachers were randomly sampled for the study. Questionnaires were used to collect data from the students, while interview schedules were used to collect data from Principals and Guidance and Counselling teachers. The validity of the research instruments was determined by experts from the department of Psychology and Educational Foundations of Jaramogi Oginga Odinga University of Science and Technology. Reliability was ascertained by the internal consistency method using Cronbach's alpha, and a reliability coefficient of $r$ above 0.7 was obtained for the questionnaire. Inferential statistics from quantitative data were analyzed using Pearson's Product correlation and regression analysis with the aid of the statistical package for social sciences (SPSS) version 22. Qualitative data from interviews were analyzed thematically. The study revealed that cognitive engagement was a significant predictor of academic achievement among secondary school students studied $(r=.376, N=312, p=.01$. The study recommended that school based teacher counsellors should utilize cognitive behavioural therapy techniques during counselling sessions with students in school in order to enhance cognitive engagement.
\end{abstract}

Keywords: relationship; student cognitive engagement; academic achievement; secondary school; students

\section{Introduction}

Many scholars interested in performance of students in school affirm that poor performance is not a problem limited to urban schools, but that many other schools the world over suffer disproportionately with among other manifestations, low academic achievement (Rumberger, 2008). Foster (2008) reports that the persistence of the attitude- achievement gap in African 
American and Latino students' beliefs and behaviours concerning academic achievement and the limited success of programmes supporting higher education for economically disadvantaged, minority students has been referenced as "paradoxical" by many researchers in the past years. It is acknowledged that education plays a key role in human development through the process of empowering people to improve their well being and participation in national building (Muthaa, M'muyuri, Bururia, and Mwenda, 2013). In Africa, Evoh (2007) notes that secondary education has continued to face several setbacks. Evoh (2007) asserts that there are serious problems in Africa with the quality of instruction, the size of classes, availability of up- to- date materials and equipment, the relevance of the curriculum to current conditions, and the integration of higher education with the world of work.

In East Africa, for instance, very poor economic conditions have characterized, and hence negatively influenced the provision of education at all levels (Evoh, 2007). Indeed, in subscribing to the ideals of the New Partnership for Africa's Development (NEPAD), even the East African countries concurred with the rest of the continent that improved secondary education is fundamental to the creation of effective human capital in any country (Evoh, 2007). However, together with the World Bank, the East African countries' scholars agree that the biggest task confronting education policymakers in this part of the world is how to transform secondary education institutions and current schooling practices to align them with the fast growing demands of globalization and the technology-driven world.

One of the factors that has been identified that could be key in transforming students' approach to their studies is student engagement. This is in recognition of the fact that research has shown student engagement and attachment to school to be important predictors of educational success. Student engagement can improve students' academic performance, promote school attendance and inhibit risky youth behaviors (Al-Alwan, 2014; Weiss and Garcia 2012). Yet, despite evidence that students' perceptions about their schoolwork and their teachers are an important determinant of performance in school, student engagement has been under-analyzed in research and policy, particularly outside of the United States and Europe (Weiss and Garcia 2012). Abbing (2013) observes that analyzing the relationship between engagement and achievement can play an important role in understanding the development of a student's school career and in predicting whether or not they manage to successfully finish their education or drop out. Engagement is considered the main model for understanding and predicting graduation of students from high school (Fall \& Roberts, 2012). Previous studies have found that students who are careful to attend all of their classes, concentrate on learning, and obey the schools' rules and regulations, generally achieve higher grades (Wang \& Holcombe, 2010). Additionally, Moretti, (2007) points out that poor school engagement can increase rates of school failure, withdrawal, dropout and problematic behavior, while Lee (2014) observes that given the relative ease with change and the positive relationships with student outcomes, student engagement should receive more attention from educators and practitioners who design and implement various interventions at school.

Literature on cognitive engagement and academic achievement exists. For example, Prusha (2012) argue that engagement played a role in students' connectedness to the content within high school classrooms and to their relationship with teachers and peers. Similarly, Robb (2014) also suggested that high grade point averages associated with higher subscale scores of the cognitive self-regulated learning strategy of organization, implying more orientation towards deeper processing. Rodriguez and Boutakidis (2013), while examining the relationship between cognitive engagement and academic achievement across three generations (immigrant, children of immigrant parent(s), non-immigrant) of $\mathbf{4 7 4}$ Mexican American adolescent students attending a junior high school in Southern California, found that for the first and second generation Mexican American students, cognitive engagement was associated with higher GPA ( $p=.041$ and $p=.019$ respectively), while for the third generation students, the relationship wasn't significant $(p=.562)$.

DeVito (2016) revealed that students who were less actively involved in learning had lower grades, were less likely to voluntarily participate in learning activities, and referred to their studying as "boring" and "useless," while the highly involved students who were often rather active participants in various in-class activities and eager respondents to teacher's questions, considered their learning to be of great value and strongly believed that it was important for their future 
education and careers.

In the U.S.A., Patel, Franco and Lindsey (2013) discovered that students in the10th grade reported greater cognitive engagement compared to peers in other grade levels, and that STEM (science, technology, engineering, mathematics) students reported their schools facilitated specific cognitive engagement behaviours more than students in the national sample at statistically significant levels. Mauro (2014) also discovered that when teachers make lessons fun and allow students to demonstrate enthusiasm and energy, they are more likely to be engaged in the class. Casuso-Holgado, Cuesta- Vargas, Moreno-Morales and Labajos-Manzanares (2013) showed that there was a significant association between engagement and academic achievement among Health Sciences students, while Valle, Regueiro, Nunez, Rodriguez, Pineiro and Rosario (2016) found a statistically significant association between the learning goals (i.e., competence and control), the approach to homework $(b=0.50, p<0.001)$, two of the variables associated with engagement in homework (the amount of homework done $[b=0.27, p<0.001]$, homework time management $[b=$ $0.30, p<0.001])$, and academic achievement $(b=0.34, p<0.001)$.

In his study in Jordan, Al-Alwan (2014) reported that cognitive engagement had a statistically significant positive correlation with academic achievement $(r=.61)$, while in Turkey, Gunuc (2014) found a significant relationship between the academic achievement score and student engagement total score $(r=.183 ; p=.002)$ as well as the sub-factors of sense of belonging and cognitive engagement $(p<.05)$. Further, Kamla-Raj and Ugur (2015) revealed that the academic performance of the students had a positive relationship with cognitive engagement $(r=.36)$.

In Nigeria, Sunday (2013) found students' task engagement to have significant, positive correlation $(r=0.74)$ with achievement in chemistry; and non-significant negative correlation $(r=-$ 0.03) with attitude toward chemistry, while Babatunde and Olanrewaju (2014), found that there was a significant relationship between academic engagement and achievement motivation among post graduate students $(r=0.967 ; P<0.05)$. Waweru and Nyagosia (2013), in Kenya, revealed that there was a significant correlation, at $p<0.05$, between the KCSE mean deviations and the overall score on time on task, while Korir and Kipkemboi (2014) established that school environment and peer made significant contribution to the students' academic performance.

\section{Research Methodology}

The research design that was employed in this study was the concurrent triangulation design, based on a mixed methods approach. In this case, the data collected were in both quantitative and qualitative forms at the same time (quantitatively by use of questionnaires with students, and qualitatively via the interview schedules used with Principals and Guidance and Counselling teachers). This study embraced the mixed methods paradigm because of the pragmatic worldview that is the philosophical assumption adopted here; pragmatic in the sense that the concern in this study was with actions, situations and consequences which are working, rather than antecedents to the study interests as say, covered in post positivism. Creswell (2009), in support of the mixed methods approach, observes that it is useful when either the quantitative or qualitative approach by itself is inadequate to best understand a research problem or the strengths of both quantitative and qualitative research can provide the best understanding. As a new concept in the analysis of the problem of academic achievement in the Kenyan context, the school engagement paradigm well fits within the mixed methods approach of inquiry, for the design has allowed for the exploration of the variables within the phenomenon with the envisaged Manga Secondary schools population, and thus the information gathered can be used for generalization to other populations bearing similar characteristics.

\section{Findings \& Discussion}

In order to investigate the relationship between cognitive engagement and academic achievement of secondary school students, the students' views were sought through the use of a Likert scale questionnaire whose items measured the constructs of cognitive engagement by the students in the learning process. Their views were summarized in frequency percentages as shown in Table 3.1. 
To corroborate the information obtained from the students, interview schedules were also used with Principals and Guidance and Counselling teachers.

Table 3.1: Students' Views on Aspects of Cognitive Engagement

\begin{tabular}{|c|c|c|c|c|c|c|c|}
\hline Items & SA & A & NS & $\mathrm{D}$ & SD & Mean & Std Dev. \\
\hline I can be creative in classroom assignments. & $67(21.5 \%)$ & $185(59.3 \%)$ & $30(9.6 \%)$ & $16(5.1 \%)$ & $14(4.5 \%)$ & 3.88 & 0.95 \\
\hline $\begin{array}{l}\text { Our school emphasizes memorizing facts and } \\
\text { figures. }\end{array}$ & $63(20.2 \%)$ & $189(60.6 \%)$ & $24(7.7 \%)$ & $18(5.8 \%)$ & $18(5.8 \%)$ & 3.84 & 1.00 \\
\hline $\begin{array}{l}\text { Our school emphasizes understanding } \\
\text { information and ideas. }\end{array}$ & $74(23.7 \%)$ & $157(50.3 \%)$ & $52(16.7 \%)$ & $17(5.4 \%)$ & $12(3.8 \%)$ & 3.85 & 0.97 \\
\hline We like analyzing ideas in-depth in class. & $75(24.0 \%)$ & $182(58.3 \%)$ & $32(10.3 \%)$ & $15(4.8 \%)$ & $8(2.6 \%)$ & 3.96 & 0.87 \\
\hline $\begin{array}{l}\text { Our teachers emphasize serious studying and } \\
\text { completing assignments. }\end{array}$ & $57(18.3 \%)$ & $176(56.4 \%)$ & $38(12.2 \%)$ & $16(5.1 \%)$ & $25(8.0 \%)$ & 3.72 & 1.07 \\
\hline $\begin{array}{l}\text { I look forward to furthering my education and } \\
\text { training beyond high school. }\end{array}$ & $68(21.8 \%)$ & $181(58.0 \%)$ & $38(12.2 \%)$ & $12(3.8 \%)$ & $13(4.2 \%)$ & 3.89 & 0.93 \\
\hline We enjoy thinking critically. & $80(25.6 \%)$ & 179 (57.4\%) & $29(9.3 \%)$ & $10(3.2 \%)$ & $14(4.5 \%)$ & 3.96 & 0.94 \\
\hline
\end{tabular}

Source: Survey data (2017)

From Table 3.1, it was evident that more than a fifth (67 in total, or $21.5 \%$ ) of the students who were sampled for the survey strongly agreed, and the majority (185 of them, translating to $59.3 \%$ ) agreed that they indeed would be creative in doing assignments. This was in contradistinction with 30 $(9.6 \%)$ who were not sure, $16(5.1 \%)$ who disagreed, and finally $14(4.5 \%)$ who strongly disagreed with the statement of the questionnaire. This revelation indicated that while a total majority of 252 out of $312(80.8 \%)$ agreed and were positive about being creative in classroom assignments (a mean of 3.88 and standard deviation of 0.95$)$, only as few as $30(9.6 \%)$ could not determine if they did so, and an equivalent population of $30(9.6 \%)$ disagreed.

From the qualitative data obtained from the principals, the concept of assignments was emphasized by the principal who commented:

'We expect our students to be creative when doing assignments since some questions are not necessarily direct. This is an effort at inculcating in them a sense of versatility in approaching national exam questions' (Principal 4)

This excerpt was an affirmation that creativity in students' approach to their assignments was a deliberately instilled skill to enable students be broad minded all the time, and hence be better prepared for tasks ahead of them. Together with students' opinions, this meant that for a vast majority, the students first appreciated the value of the assignments, and then put in a sense of creativity in order to accomplish their best in the assignments, as a preparatory measure for their summative evaluation by the Kenya National Examinations Council. This would at best be accomplished by the students engaging in deep processing of information, and would be in agreement with Robb (2014) who reported a positive relationship between deep processing and GPA.

A total of $63(20.2 \%)$ of the students strongly agreed, and189 $(60.6 \%)$ of them agreed with the statement: "Our school emphasizes memorizing facts and figures". Only $24(7.7 \%)$ were not sure, and $18(5.8 \%)$ plus another $18(5.8 \%)$, making a total of $36(11.6)$ strongly disagreed or disagreed. From the point of view of Bloom's taxonomy regarding the supposed cognitive levels of difficulty of learning content, this kind of majority agreement (with a mean of 3.84 and standard deviation of 1.00 ) would be an indication of schools emphasizing the very basic or shallow levels of information processing, which may not augur so well for academic success. The foregoing scenario appeared to contradict the information obtained from the students regarding the statement "Our school emphasizes understanding information and ideas" which drew almost equal responses of 74 $(23.7 \%)$ strongly agreeing, and a further 157 students $(50.3 \%)$ agreeing, compared with $52(16.7 \%)$ who were not sure, $17(5.4 \%)$ who disagreed, and $12(3.8 \%)$ who strongly disagreed. This kind of overwhelming endorsement of deeper information processing (with a mean of 3.85, standard 
deviation of 0.97 ) was a clear indication of the promotion of better perspectives of posting good academic results.

The questionnaire item "We like analyzing ideas in-depth in class" registered 75 students $(24.0 \%)$ who strongly agreed with it and $182(58.3 \%)$ who agreed, while $32(10.3 \%)$ were not sure whether they did so, as $15(4.8 \%)$ disagreed, and another 8 (2.6\%) strongly disagreed. Evidently, the majority approval indicated by those who agreed (257 students, forming $82.3 \%$, a mean of 3.96 , standard deviation of 0.87 ) was an affirmation that deep processing of information for the sake of a more lasting understanding of concepts was encouraged in the studied schools.

Qualitative data from principals supported the above finding. One principal said:

'Our system allows students to constitute their groups where they are expected to subject the content we have studied in class to thorough discussion and analysis. This enables all of the students to be at the same level with one another in terms of understanding.' (Principal 10)

This excerpt acknowledged that students gain better understanding of academic concepts when they engage in further discussion of content in an analytical manner. At the same time, it is an appreciation of the strength of co-operative effort in support of one another as a measure undertaken by students in their academic endeavours. This revelation was in agreement with Kamla-Raj and Ugur (2015) who found that elaborative processing was significantly related to student achievement.

Further to the above findings, 57 of the students in the survey (18.3\%) recorded very strong agreement, with a further $176(56.4 \%)$ in agreement with the statement: "Our teachers emphasize serious studying and completing assignments". This left only a minority of $38(12.2 \%)$ not being sure, $16(5.1 \%)$ disagreeing, and $25(8.0 \%)$ strongly disagreeing with the statement. The scenario presented here is that with sustained effort in doing and completing assignments, majority of the students ( 233 , forming $75 \%$, a mean of 3.72 , standard deviation of 1.07 ) would be getting better mechanisms of internalizing the academic concepts being covered, and at the same time, getting used to KCSE examination questioning. As a consequence, they may do better in their exams. This finding is in concurrence with Latif and Miles (2011) who found a positive relationship between graded assignments and improved performance among students.

Qualitative data sourced from the principals and Guidance and Counselling teachers in the studied schools also confirmed that in some instances, students' cognitive engagement was exhibited in the form of classroom tasks and assignments. These tasks and assignments are academic exercises that the students are given to do as individuals, but must be completed during class hours. For answers, they may refer to the class text books, their own notes and any other reference materials at their disposal in class. The essence of this is to intensify critical thinking and a sense of self-initiative in academic work. They learn how to analyze ideas and concepts, and to come up with their own evaluation, approach and solution to the various academic tasks or assignments given. That kind of initiation is anticipated to enhance the students' chances of success in academic achievement. One of the Principals had this to say:

'Classroom assignments are given to encourage critical thinking and to emphasize understanding of concepts. This is in order to ensure retention of academic content and hence lead to improved performance in examinations' (Principal 11)

This is an indication that the Principals and teachers attached great importance to the classroom assignments in the belief that they stimulate the thinking faculties of the students and hence improve their ability to retain information that they have learnt. The import of all this is that the questions given as assignments will enable the students to get further opportunity to be in touch with the content learnt in class. This is agreement with Mauro (2014) who found that when teachers provide opportunities for asking questions and reviewing learnt materials, the students feel more engaged in the learning process. However, Rodriguez and Boutakidis (2013), on their part, found no significant relationship between cognitive engagement and academic achievement among third generation Mexican American students.

The teachers emphasized, however, that these classroom assignments must be very closely 
monitored and supervised. In this regard, one teacher observed:

'The students are cognitively engaged through classroom exercises and assignments, which, however, must be duly checked and marked. This affects them positively, and encourages further effort and critical thinking. This helps inculcate a sense of deeper thinking that they hence employ in examinations, and ultimately improved academic performance'(Teacher 8)

From the excerpt above, it emerged that when teachers check and mark the classroom exercises, the students would take them more seriously. At the same time, the assignments inculcate in the students some aspect of critical thinking, which is a necessary ingredient for academic achievement. These assertions are in tandem with those of Latif and Miles (2011), who argued that if graded assignments are a course requirement, students will be motivated to study and work on the assignments, and consequently their grades are expected to improve. Latif and Miles (2011) also added that if assignments are closely related to test questions, then students who do the assignments are more likely to do well on the test, and finally that students may be more interested in participating in classes if they believe that participation will help them to do well on the assignments, and such class participation may also have a positive independent effect on course grades. In contrast to this argument, however, Robb (2014) found no significant relationship between grade point average and rehearsal among pre-licensure baccalaureate millennial nursing students.

Regarding any further ambitions in the realms of academia and as a harbinger of cognitive engagement, the findings of the study revealed that majority of the students surveyed would wish to further their studies, with $68(21.8 \%)$ strongly agreeing, and $181(58 \%)$ agreeing, making a total of 249 of the students $(79.8 \%$ mean $=3.89$; Std Dev. $=.93)$. Only $38(12.2 \%)$ were not sure, with a further $12(3.8 \%)$ disagreeing, and $13(4.2 \%)$ strongly disagreeing.

Generally, Guidance and Counselling teachers most particularly would be interested in knowing the overall students' response to the statement: "I look forward to furthering my education and training beyond high school" because it would be the epitome of cognitive ambition and would greatly define their cognitive engagement. It would also serve as the entry point for Guidance and Counselling service provision, since the teacher counsellor would use the knowledge to design inspirational programmes for the students. Thus, qualitative data revealed the feelings of the teachers as follows:

'Most hard working students will concentrate fully on their academic exercises, with an eye on their future careers.' (Teacher 2)

This excerpt was an affirmation of the importance of ambition for further studies by the students, as the driving force behind their hard work.

Further to the above scenario, a significant majority of 256 of the students, translating to $83 \%$ of those who took part in the survey indicated that they enjoyed thinking critically (mean=3.96; Std Dev.=.94). Out of this population, $80(25.6 \%)$ strongly agreed, while $179(57.4 \%)$ agreed. Only 29 student respondents (9.3\%) were not sure, while $10(3.2 \%)$ disagreed, and $14(4.5 \%)$ strongly disagreed. Such critical thinking by students would most likely be exhibited when working on assignments, or projects assigned to them and is critical in facilitating understanding of academic content for the sake of retention. The finding seemed to concur with that of Sunday (2013) who found a significant relationship between students' task engagement and their academic achievement. In this regard, qualitative data from the interviews with principals and Guidance and Counselling teachers indicated that the use of project work in schools enhanced academic achievement among students. According to the Guidance and counselling teachers and Principals interviewed, project work here involved students coming up with scientific-based innovations of how things work. They are expected to come up with the topic, do research on it, and do a write-up on how the project can benefit the society. This would mostly be for the sake of the Science and Engineering Fair, a competition organized for schools. For example, one of the teachers said:

Learners are creatively engaged in project work, particularly during the preparations for Science 
and Engineering Fair. They are encouraged to make accurate observations, record and interpret results. This creativity has resulted in enhanced performance even in languages and solving statistical problems in maths and sciences' (Teacher 1)

From that interview excerpt, it was evident that use of project work enhanced academic achievement among students. At the same time, project work was significant in promoting creative thinking and analytical skills of the learners. In the process, it would be expected to broaden the knowledge range of the learners, hence improved academic performance. This finding agreed with Prusha (2012) who concluded that students who are engaged-meaning that they are focused, committed, and participating in self-regulated learning in school-have, on average, better grades, higher test scores, and higher rates of matriculation to post-secondary education.

To investigate whether there was any significant relationship between cognitive engagement and academic achievement, the null hypothesis was stated thus:

$\mathrm{Ho}_{1}$ : There is no statistically significant relationship between cognitive engagement and academic achievement among secondary school students in Manga Sub County, Nyamira County.

To test the hypothesis, a Pearson Product Moment Correlation Coefficient was computed, with scores on cognitive engagement as an independent variable and level of academic achievement as the dependent variable. The scores of cognitive engagement which were computed from frequencies of the students' responses were converted into a continuous scale by calculating the mean of the responses per respondent, where high scale ratings implied high cognitive engagement and vice versa. The correlation analysis result was as shown in the SPSS output in Table 3.2.

Table 3.2: The Relationship between Cognitive Engagement and Academic Achievement

\begin{tabular}{llc}
\hline & & Academic achievement \\
\hline \multirow{3}{*}{ Cognitive engagement } & Pearson Correlation & $.376 "$ \\
& Sig. (2-tailed) & .000 \\
& $\mathrm{~N}$ & 312 \\
\hline${ }^{*}$. Correlation is significant at the 0.01 level (2-tailed).
\end{tabular}

The finding showed that there was a moderate positive relationship between cognitive engagement and academic achievement $(r=.376, N=312, p<.05)$, with increase in cognitive engagement resulting in an increase in academic achievement. The relationship was statistically significant; therefore, the hypothesis that "there is no statistical significant relationship between cognitive engagement and academic achievement" was rejected. For that reason, it was concluded that student cognitive engagement had a direct positive influence on the student academic achievement. That is to say, students who cognitively engage more in the learning process reflect better academic achievement than those less cognitively engaged. This finding agreed with Robb (2014) and Gunuc (2014), who found strong positive correlation between cognitive engagement and academic achievement. However, the same finding was in disagreement with the findings of Rodriguez and Boutakidis (2013) for their third generation Mexican-American students, among whom there wasn't a significant relationship between cognitive engagement and academic achievement.

Qualitative data obtained from the Guidance and Counselling teachers seemed to corroborate this finding. It emerged, for instance, that students who don't take their assignments seriously wouldn't stand a chance of achieving success in their academic endeavours. As a result, the students required consistent supervision in order to ensure that they got actively engaged cognitively, for them to succeed. A teacher thus said:

"Sometimes the students do so poorly in the assignments, if they are not supervised. This is because some of them are not serious with their studies and only a few look forward to furthering their studies. For those who are serious and take the assignments seriously as learning points, they develop better retention skills of academic content, hence improved performance. For those who don't, their performance is always average or below average" (Teacher 6) 
This excerpt was a clear declaration by the teacher six of the fact that the use of assignments is a process that would lead to enhanced content retention; hence a chance for better academic achievement, and that lack of seriousness with them (assignments) would definitely stifle success. To further illustrate the relationship between cognitive engagement and academic achievement, a scatter plot was generated as shown in Figure 1.

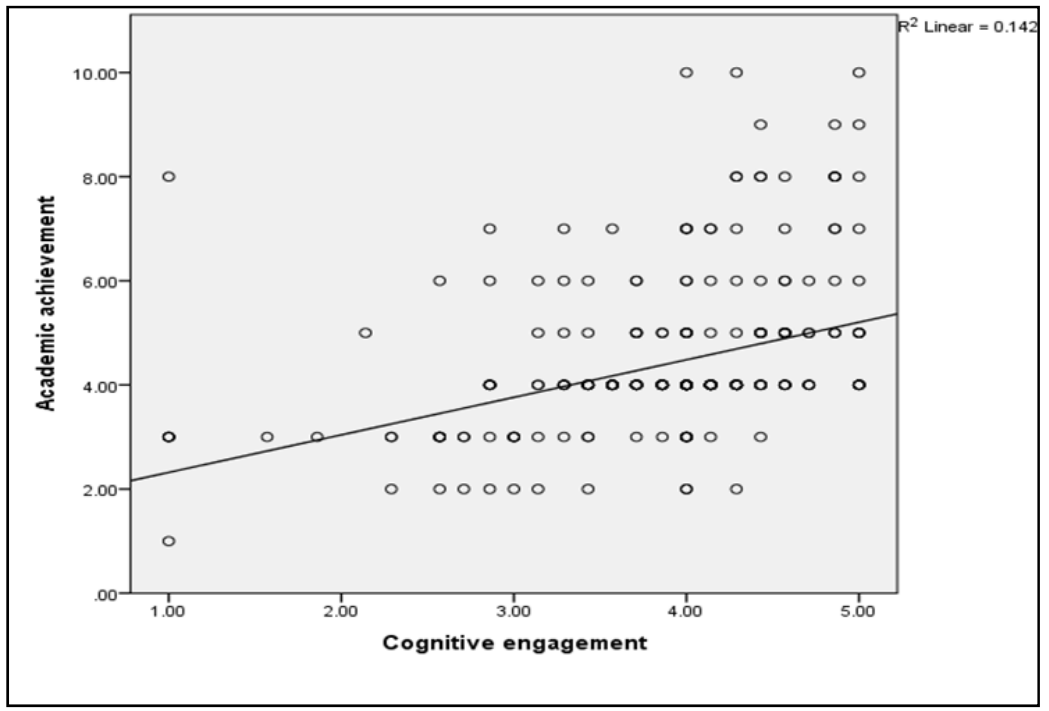

Figure 1: Scatter plot of the Relationship between cognitive engagement and academic achievement

The scatter plot indicates that there was a moderate positive correlation between cognitive engagement and academic achievement. It is almost clear that the pattern of dots slopes from lower left to upper right, indicating a positive correlation between the two variables. The line of best fit (trend line) further reveals that there was correlation between the variables. The scatters tend to concentrate in the vicinity of the identity line, meaning the relationship was real and not by chance. This result was in concordance with that of Rodriguez and Boutakidis (2013) who found cognitive engagement to be significantly associated with higher GPA scores among first and second generation Mexican Americans, though the same could not be said of the third generation Mexican American students that they studied.

Other than the existence of a positive relationship between cognitive engagement and academic achievement as exhibited above, the current study sought to estimate the level of influence of cognitive engagement. This was achieved by computing a coefficient of determination $\left(R^{2}\right)$, which was done by using regression analysis and the results were as shown in Table 3.3.

Table 3.3: Model Summary on Regression Analysis of Influence of Cognitive Engagement on Academic Achievement

\begin{tabular}{lcccc}
\hline Model & $\mathrm{R}$ & $\mathrm{R}$ Square & Adjusted R Square & Std. Error of the Estimate \\
\hline 1 & $.376^{\mathrm{a}}$ & .142 & .139 & 1.28284 \\
\hline a. Predictors: (Constant), Cognitive engagement & \\
b. Dependent Variable: Academic achievement &
\end{tabular}

The model shows that cognitive engagement accounted for $14.2 \%$, as signified by coefficient of $\left(R^{2}\right.$ $=.142$ ), of the variation in the level of academic achievement among secondary school students. 
This was a fairly large effect from one independent variable on the dependent variable in this study, for this cohort of students. Further, to determine whether cognitive engagement was a significant predictor of academic achievement Analysis of Variance (ANOVA) was computed as in Table 3.4.

Table 3.4: ANOVA -Influence of Cognitive Engagement on Academic Achievement

\begin{tabular}{lccccc}
\hline Model & Sum of squares & Df & Mean square & $F$ & Sig. \\
\hline Regression & 84.137 & 1 & 84.137 & 51.126 & $.000^{b}$ \\
Residual & 510.158 & 310 & 1.646 & & \\
Total & 594.295 & 311 & & & \\
\hline A. & Depent & & & &
\end{tabular}

A. Dependent variable: Academic achievement

B. Predictors: (constant), Cognitive engagement

From Table 3.4, it can be noted that cognitive engagement was a significant predictor of academic achievement $[F(1,310)=51.126, p<.05)$. This means that cognitive engagement really influenced academic achievement among the secondary school students in this study since cognitive engagement explained a significant amount of the variance in the level of academic achievement. This finding was in tandem with that of Gunuc (2014) who found a significant relationship between the academic achievement score and student cognitive engagement.

For further confirmation on the relative influence of the aspects of cognitive engagement incorporated in this study, a linear regression was generated to find the actual influence of cognitive engagement on academic achievement, as shown in Table 3.5.

Table 3.5: Coefficients of Linear Regression: Cognitive Engagement and Academic Achievement

\begin{tabular}{|c|c|c|c|c|c|c|}
\hline \multirow[t]{2}{*}{ Model } & \multicolumn{2}{|c|}{$\begin{array}{c}\text { Unstandardized } \\
\text { coefficients }\end{array}$} & \multirow{2}{*}{$\begin{array}{c}\begin{array}{c}\text { Standardized } \\
\text { coefficients }\end{array} \\
\text { Beta }\end{array}$} & \multirow[t]{2}{*}{ Sig. } & \multicolumn{2}{|c|}{$\begin{array}{c}95.0 \% \text { confidence } \\
\text { interval for B }\end{array}$} \\
\hline & $\mathrm{B}$ & Std. Error & & & Lower bound & Upper bound \\
\hline 1 (Constant) & $\begin{array}{l}1.599 \\
721\end{array}$ & $\begin{array}{l}.397 \\
101\end{array}$ & 376 & $\begin{array}{l}4.025 \\
7.150\end{array}$ & $\begin{array}{rr}.000 & .817 \\
000 & 523\end{array}$ & $\begin{array}{c}2.380 \\
919\end{array}$ \\
\hline
\end{tabular}

a. Dependent variable: Academic achievement

It is evident from Table 3.5 that, if the cognitive engagement of the students was increased by one standard deviation, then scores of academic achievement would improve by .376 standard deviation units. This is substantial effect from one independent variable. To underline, hence, the significant contribution of such a variable, qualitative data generated from this study revealed that teachers used a number of strategies to ensure cognitive engagement, and hence sustain better or improved academic achievement. These were: homework, use of group and class discussions, continuous assessment tests/ random assessment tests and end of term examinations.

Apart from the intention of them keeping the students in touch with academic content even when they are at home, homework was provided to students to learn to do further research on their own, hence get the skill of self-cordination and analytical perspectives in academic pursuit. At the same time, it is expected to assist in accelerating syllabus coverage, as some aspects of topics are covered in the assignments, and teachers just gloss over the those areas in form of quick revision, to ensure that students have thoroughly mastered the content that they are given. According to Principal number 3:

'Students are exposed to assignments even when they are at home. This is meant to improve their critical thinking skills, and the ability to reason on their own. They also stay focused on their studies, and this is anticipated to boost their performance' (Principal 3)

The above excerpt, apart from emphasizing the importance of homework as a panacea for students' academic orientation even when they are at home, also intimated that the critical thinking faculties of the students are stimulated when they undertake to do their homework. This would in turn, engender easy academic success. 
Group discussions, also mentioned by the respondents, involve students being put in groups, mostly based on mixed abilities, and are given different tasks to research on, discuss and consolidate into notes in various subject areas. The group discussions are monitored in class, and where difficulties arise, the teacher is handy to provide assistance. They are organized during class hours; that is, when the lesson is on, or during remedial times after normal lessons. According to the teachers, they are expected to give learners the opportunity to learn collaboratively, borrow from each other's experience, develop negotiation skills, as well as generate new information quickly. One Principal said:

'When they prepare for the group discussion exercises, they are also encouraged to do research in the library. This is expected to create a sense of aggressiveness in search of knowledge and hence accelerate their mastery of academic content, and ultimately better performance' (Principal 6)

This implies that the more students get used to research in the library, the more curious they become for further academic inquiry, and this would become an embedded habit in them. Consequently, a sense of improved performance would arise from the constant pursuit of information. Still regarding group discussions, one of the teachers said:

'The group discussions are used to promote further understanding of academic content after teaching' (Teacher 11)

From the excerpt, it can be inferred that the content given to the students for discussion is derived from what has been taught, so that it is used to probe further how much the students have learnt. When then the discussions are successfully held, the content hitherto covered but not understood would be internalized. This revelation agreed with Mauro (2014) who observed that when teachers provide opportunities for students to ask questions, discuss and review material learnt, they are more likely to feel engaged.

Continuous assessment tests/ random assessment tests, it emerged from the respondents in this study, are tests administered to the students periodically, based on the topics that have been covered in the course of the term. They are variously referred to as Continuous Assessment Tests or Random Assessment Tests, depending on the school system. They are meant to keep the students reading what has been taught in the term. The intention is to occupy them so that they do not stay idle, while at the same time, they are reminded continuously of the content already covered. This is in order to boost the retention of what is already covered, and hence better academic performance.

One Principal reported:

'There is intense focus on deeper understanding of content. Therefore, random tests are given to ensure mastery of academic work covered' (Principal 9)

From this excerpt, it is evident that the tests given are meant to draw students first into intense concentration on their studies as they make preparations to tackle those tests. That concentration would facilitate deeper understanding of content, and subsequently give room for the ability to answer correctly, the questions based on covered contents. This finding agreed with Sunday (2013) whose study revealed that students' task engagement had a significant positive correlation with achievement in chemistry.

\section{Conclusion}

From this study, it was concluded that cognitive engagement was a significant predictor of academic achievement among secondary school students. This was concluded from the statistical results obtained from the Pearson Product Moment Correlation Coefficient and the ANOVA computation revealed that cognitive engagement was a significant predictor of academic achievement. It was observed in this study that students enjoyed critical thinking, analyzing ideas in 
depth in class, and the teachers as well emphasized serious studying. It also emerged that project work, classroom assignments; homework as well as group discussions were significant in engaging the students. The study recommended that school based teacher counsellors should utilize cognitive behavioural therapy techniques during counselling sessions with students in school in order to enhance cognitive engagement.

\section{References}

Abbing, J. (2013).The Effect of Students' Engagement on Academic Achievement in Different Stages of their Academic Career from a Drop out Perspective. Published Bachelor's Thesis, University of Twente, Canada.

Al-Alwan A. F. (2014). Modeling the Relations among Parental Involvement, School Engagement and Academic Performance of High School Students. International Education Studies; 7(4) pp 47-56.

Babatunde, M. M. \& Olanrewaju, M.K. (2014). Predictive Influence of Students' Academic Engagement and Academic Self-Concept on Achievement Motivation among Post Graduate Students in University of Ibadan, Oyo State, Nigeria. International Journal of Science and Research (IJSR) Volume 3 Issue 5, pp 497-503.

Casuso-Holgado, M. J.; Cuesta- Vargas A. I., Moreno-Morales N. \& Labajos-Manzanares, M. (2013). The association between academic engagement and achievement in health sciences students. BMC Medical Education 2013, 13:33 Pp 1-7. http://www.biomedcentral.com/1472-6920/13/33

Creswell, J. W. (2009). Research Design: Qualitative, Quantitative, and Mixed Methods Approaches. Thousand Oaks, CA: Sage Publications.

DeVito, M. (2016). Factors Influencing Student Engagement . Unpublished Thesis, Sacred Heart University, Fairfield, CT. Retrieved from http://digitalcommons.sacredheart.edu/edl/11

Evoh, C. J. (2007). Policy Networks and the Transformation of Secondary Education Through ICTs in Africa: The Prospects and Challenges of the NEPAD e- schools Initiative. In The International Journal of Education and Development Using ICT. 3(1) 2007 98-123

Fall, A \& Roberts, G. (2012). High school dropouts: Interactions between social context, self-perceptions, school engagement, and student dropout. Journal of Adolescence, Volume 35, Issue 4, Pages 787-798

Foster, K. C. (2008). The Transformative Potential of Teacher Care as Described by Students in a Higher Education Access Initiative. Education and Urban Society. Vol 41 Number1 November 2008 pp 34-47

Gunuc, S. (2014).The Relationships between Student Engagement and Their Academic Achievement. International Journal on New Trends in Education and Their Implications. Volume: 5 Issue: 4 pp 216-231.

Kamla-Raj \& Ugur Dogan(2015). Student Engagement, Academic Self-efficacy, and Academic Motivation as Predictors of Academic Performance. Anthropologist, 20(3): 553-561

Korir, D. K. \& Kipkemboi, F. (2014). The Impact of School Environment and Peer Influences on Students' Academic Performance in Vihiga County, Kenya. International Journal of Humanities and Social Science Vol. 4, No. 5(1) pp 240-251.

Latif, $\mathrm{E}$ and Miles, S (2011). The impact of Assignments on Academic Performance. Journal of Economics and Economic Education Research, Volume 12, Number 3, 2011 pp 1-11

Lee, J. S. (2014). The Relationship between Student Engagement and Academic Performance: Is It a Myth or Reality? Journal of Educational research.107 (3), 2014, pages 177-185 published on line $26^{\text {th }}$ March 2014. DOI:10.1080/00220671.2013.807491. ScienceDirect. 5th World Conference on Educational Sciences WCES 2013

Mauro, C. (2014). "Middle School Students' Perceptions on Academic Motivation and Student Engagement" Counselor Education Masters Theses. Paper 172.The College at Brockport, cball1@brockport.edu

Moretti, E. (2007). Crime and the costs of criminal justice. In C. Belfield, \& H. Levin (Eds.), The price we pay: Economic and social consequences of inadequate education (pp. 142-159). Washington, DC: Brookings Institution press.

Muthaa, G. M.; M'muyuri, M. M., David Bururia, D.; \& Mwenda, E. E. (2013). Dropout among Male Pupils in Primary Schools of Igembe District, Kenya. Creative Education 2013. 4(3), 180-184 Published Online March 2013 in SciRes (http://www.scirp.org/journal/ce) DOI:10.4236/ce.2013.43026

Prusha, J. A. (2012). Voices of High School Seniors: Perceptions of National Honor Society Students Regarding Their Cognitive Engagement in High School. A published PhD thesis. lowa State University, lowa.

Robb, M. K. (2014). Factors That Influence Cognitive Engagement and Academic Success of Pre-Licensure Baccalaureate Millennial Nursing Students. A published Phd Thesis. Indiana University of Pennsylvania.

Rodriguez, J., \& Boutakidis, L. P. (2013). The Association between School Engagement and Achievement across Three Generations of Mexican American Students. Association of Mexican-American Educators (AMAE) Journal 7(1). Pp 5-12

Rumberger, R. (Ed.). (2008). Engaging High School Students in school. California: National Research Council. 
Sunday, O. (2013). Relationships between students' task engagement and learning outcomes in chemistry. Journal of Educational Research and Reviews Vol. 1(1), pp. 1-8.

Valle, A.; Regueiro, B; Nunez, J. C. Rodriguez, S.; Piñeiro, I. \& Rosário, P. (2016). Academic Goals, student Homework Engagement, and Academic Achievement in Elementary School Front.Psychol.7:463. doi: 10.3389/fpsyg.2016.00463 Pp 1-10

Wang, M.T \& Holcombe, R. (2010). Adolescents' Perceptions of School Environment, Engagement, and Academic Achievement in Middle School. American Educational Research Journal, 47, 633-662. http://dx.doi.org/10.3102/0002831209361209.

Waweru, S. \& Nyagosia, P. (2013). Utilization of Allocated Time and Academic Achievement: A Survey of Secondary School Students in Kenya. International Journal of Education and Research 1(6). Pp 128-134

Weiss, C. C. \& García, E. (2012). Student Engagement and Academic Performance in México: Evidence and Puzzles from PISA. New York: Columbia University 